\title{
Distribuição e potencial erosivo das chuvas no Estado do Tocantins
}

\author{
Marcelo Ribeiro Viola(1), Junior Cesar Avanzi(2), Carlos Rogério de Mello(3), \\ Saulo de Oliveira Lima(1) e Marcos Vinicius Giongo Alves ${ }^{(1)}$
}

\begin{abstract}
(1)Universidade Federal do Tocantins, Campus de Gurupi, Rua Badejós, Lote 7, Chácaras 69/72, Zona Rural, Caixa Postal 66, CEP 77402-970 Gurupi, TO, Brasil. E-mail: mrviola@uft.edu.br, saulolima@uft.edu.br, giongo@uft.edu.br (2)Embrapa Pesca e Aquicultura, Núcleo de Sistemas Agrícolas, 104 Sul, Avenida LO 01, no 34, Conjunto 4, $1^{\circ}$ e $2^{\circ}$ pavimentos, CEP 77020-020 Palmas, TO, Brasil. E-mail: junior.avanzi@embrapa.br (3)Universidade Federal de Lavras, Departamento de Engenharia, Caixa Postal 3037, CEP 37200-000, Lavras, MG, Brasil. E-mail: crmello@deg.ufla.br
\end{abstract}

Resumo - O objetivo deste trabalho foi determinar os valores de erosividade e gerar os mapas da distribuição espaço-temporal das chuvas no Estado do Tocantins. Analisaram-se séries históricas pluviométricas de 97 postos pluviométricos, compreendendo o período de 1985 a 2009. A erosividade foi estimada por meio de equações nas quais a variável independente foi a precipitação média mensal ou o coeficiente de chuva de Fournier (Rc). A geoestatística foi aplicada para o mapeamento da erosividade tanto na escala mensal quanto na anual. A erosividade anual apresentou valores entre $6.599 \mathrm{e} 14.000 \mathrm{MJ} \mathrm{mm} \mathrm{ha}^{-1} \mathrm{~h}^{-1}$, com auge em dezembro, quando atingiu valores de até $2.800 \mathrm{MJ} \mathrm{mm} \mathrm{ha}^{-1} \mathrm{~h}^{-1}$ por mês. De maio a setembro, a erosividade apresentou valores inferiores ao crítico, tido como $500 \mathrm{MJ} \mathrm{mm} \mathrm{ha}^{-1} \mathrm{~h}^{-1}$ por mês. Foram identificadas três regiões prioritárias para ações de planejamento visando a conservação do solo e da água: região centro-oeste do Estado, nas imediações do Parque Estadual do Cantão, com maior erosividade anual; região norte do Estado, especialmente no primeiro trimestre; e região sudeste do Estado, no quarto trimestre.

Termos para indexação: conservação de solo e água, índice de erosividade da chuva, erosão hídrica, geoestatística, mapeamento.

\section{Distribution and erosive potential of rainfall in the state of Tocantins, Brazil}

\begin{abstract}
The objective of this work was to determine rainfall erosivity values and to generate its spatial-temporal distribution maps in the state of Tocantins, Brazil. Pluviometric historical series from 97 rain gauges were analyzed, covering the period from 1985 to 2009. Erosivity was estimated by equations in which the independent variable was the average monthly rainfall or the Fournier rainfall index (Rc). Geostatistics was applied for mapping erosivity both monthly and annually. Annual erosivity values varied between 6,599 and $14,000 \mathrm{MJ} \mathrm{mm} \mathrm{ha}^{-1} \mathrm{~h}^{-1}$, with peak in December when it reached values up to 2,800 $\mathrm{MJ} \mathrm{mm} \mathrm{ha}{ }^{-1} \mathrm{~h}^{-1}$ per month. From May to September, erosivity values had lower than the critical one, considered $500 \mathrm{MJ} \mathrm{mm} \mathrm{ha}^{-1} \mathrm{~h}^{-1}$ per month. Three priority regions were identified for soil and water conservation planning activities: mid-west region of the state, in the neighborhood of Cantão State Park, with greatest erosivity; northern region of the state, especially during the first quarter of the year; and southern region of the state, in the fourth quarter.
\end{abstract}

Index terms: soil and water conservation, rainfall erosivity index, soil water erosion, geostatistics, mapping.

\section{Introdução}

O Estado do Tocantins encontra-se em uma zona de transição geográfica entre o Cerrado e a Floresta Amazônica, na divisa com a região Nordeste do Brasil. Esse posicionamento geográfico contribui para uma grande variabilidade climática (Tocantins, 2012) e, consequentemente, para o potencial erosivo da chuva.

As características físicas de um evento de precipitação, tais como tamanho, forma e velocidade final da gota de chuva, bem como intensidade, tipo de chuva (convectiva, frontal ou orográfica) e sua localização geográfica, são primordiais para a avaliação do seu potencial erosivo (Mello et al., 2013). O potencial erosivo da chuva, definido como erosividade da chuva, pode ser calculado por meio da análise de dados pluviográficos. Contudo, nas condições brasileiras, essas informações nem sempre são encontradas, ou, quando disponíveis, há falhas ao longo do período de observação ou são insuficientes 
para mapeamento (Aquino et al., 2012). Desse modo, o índice de erosividade da chuva $\left(\mathrm{EI}_{30}\right)$, que consiste no produto da energia cinética total da chuva pela sua intensidade máxima em 30 min consecutivos, tem sido frequentemente determinado por correlações com os registros pluviométricos mensais e anuais por meio do coeficiente de chuva de Fournier (Mello et al., 2007; Oliveira et al., 2012a).

O conhecimento da erosividade, tanto no espaço quanto no tempo, é fundamental para o planejamento de práticas de manejo e de conservação do solo e da água que visam minimizar os efeitos adversos da erosão hídrica. Nesse sentido, diversos pesquisadores têm realizado estudos da distribuição espacial da erosividade mensal e anual para identificar o período e as regiões de maior risco à erosão, com destaque para os trabalhos de Silva (2004), Oliveira et al. (2012b) e Mello et al. (2013), em todo território nacional; Mello et al. (2007) e Aquino et al. (2012), em algumas regiões de Minas Gerais; Oliveira et al. (2012a), no Estado do Mato Grosso do Sul; Silva et al. (2010) e Mello et al. (2012), no Estado do Espírito Santo; e Montebeller et al. (2007), no Estado do Rio de Janeiro.

Em termos globais, a erosividade também tem sido objeto de estudo de vários pesquisadores. Sanchez-Moreno et al. (2014) mapearam a erosividade para a Ilha de Santiago, em Cabo Verde; Diodato et al. (2013) estimaram a erosividade para o continente Africano; Khorsandi et al. (2012), para a região norte do Irã; e Petan et al. (2010), para a parte mediterrânea da Eslovênia. Nesses estudos, a geoestatística tem sido amplamente empregada, pois permite a análise da distribuição espacial entre as observações, o que determina, por meio de semivariograma, a distância na qual existe a dependência espacial (Silva et al., 2010). Desse modo, a modelagem eficaz do semivariograma torna-se fundamental, pois todo o processo subsequente de interpolação depende do fato de essa modelagem representar a estrutura de continuidade espacial do fenômeno em estudo (Goovaerts, 1999; Mello et al., 2012).

A espacialização da erosividade, representada por mapas, é alternativa eficaz para contornar a escassez de dados que possibilitem a determinação dos índices de erosividade em localidades que carecem dessas informações, em especial para o Estado do Tocantins, que encontra-se atualmente em franca expansão agrícola. Ressalta-se, ainda, que, muitas vezes, essa ocupação agropecuária ocorre em regiões de elevado índice pluvial e solos de baixa resistência à erosão, como os Neossolos Quartzarênicos.

O objetivo deste trabalho foi determinar os valores de erosividade e gerar os mapas da distribuição espaço-temporal das chuvas no Estado do Tocantins.

\section{Material e Métodos}

Os dados utilizados no presente trabalho foram obtidos do Sistema de Informações Hidrológicas (HidroWEB) da Agência Nacional de Águas (ANA). De um total de 160 postos pluviométricos disponíveis para o Estado do Tocantins e proximidades, foram selecionadas séries históricas de 97 localidades, com monitoramento no período de 1985 a 2009, tendo-se realizado análise de consistência pelo método da dupla massa, conforme descrito por Tucci (2004). Do total selecionado, 87 postos foram utilizados para calibração dos modelos de espacialização, e os demais, para validação do preditor geoestatístico, procedimento também adotado por Viola et al. (2010) e Mello et al. (2013).

$\mathrm{Na}$ região do entorno do Estado do Tocantins, Oliveira Junior (1996) para o Estado do Pará, Silva et al. (1997a) para o Estado de Goiás, Silva (2004) para o Estado da Bahia e Almeida (2009) para o Estado de Mato Grosso apresentaram equações para estimativa da erosividade da chuva em estações principais, que dispõem de registros pluviográficos (Tabela 1). Essas equações assumem como variável independente a precipitação média mensal (p) ou o índice de Fournier $(\mathrm{Rc})$. Para a definição da área de influência de cada estação principal, utilizou-se o índice de concentração da precipitação (ICP), que pode ser entendido como uma medida da distribuição temporal e sazonal da precipitação, e calculado de acordo com a equação (Oliver, 1980):

$$
\operatorname{ICP}_{\text {ANUAL }}(\%)=\sum_{i=1}^{12} \mathrm{p}_{i}^{2} /\left(\sum_{i=1}^{12} \mathrm{p}_{\mathrm{i}}\right)^{2} \times 100 .
$$

Nesse sentido, dentro de uma classe homogênea de ICP, espera-se um mesmo padrão de precipitação e, consequentemente, de erosividade (Oliver, 1980; Michiels et al., 1992). O cálculo da erosividade de cada posto pluviométrico foi realizado a partir da equação de uma estação principal inserida na mesma região homogênea de ICP. Contudo, considera-se que, no interior de uma região homogênea de ICP, 
podem ocorrer mais de uma estação principal. Assim, aplicou-se a metodologia dos polígonos de Thiessen para determinar a área de influência das estações principais que se inserem em uma mesma classe de ICP (Figura 1 A). Desse modo, calculou-se a erosividade da chuva para cada posto pluviométrico com base na equação gerada para a respectiva região de influência.

A variável explicativa para o cálculo do índice $\mathrm{EI}_{30}$ foi o índice de Fournier, que, segundo Renard \& Freimund (1994), é obtido pela seguinte equação: $\mathrm{Rc}=\mathrm{p}^{2} / \mathrm{P}$, em que Rc é o coeficiente de chuva (mm) para o mês em questão; p é a precipitação média mensal (mm); e P é a precipitação média anual (mm). Para as localidades na região de influência da estação principal de Belém, a variável explicativa para o cálculo de $\mathrm{EI}_{30}$ foi a precipitação média mensal (p). A justificativa para a utilização dessa estação se fundamenta na escassez de estudos dessa natureza ao norte do Estado do Tocantins, onde o regime pluvial apresenta características peculiares, o que requer o emprego da informação existente para a adequada representação do padrão de erosividade local. Após obtenção do Rc, procedeu-se à estimativa do índice $\mathrm{EI}_{30}$, em $\mathrm{MJ} \mathrm{mm} \mathrm{ha}^{-1} \mathrm{~h}^{-1}$ por mês, conforme

Tabela 1. Equações para estimativa do índice de erosividade padrão $\left(\mathrm{EI}_{30}\right)$, em função do índice de Fournier $(\mathrm{Rc})$ e da precipitação média mensal (p), disponíveis nas proximidades do Estado do Tocantins.

\begin{tabular}{|c|c|c|c|c|c|}
\hline Estação & Equação & Estado & Latitude & Longitude & Referência \\
\hline Conceição do Araguaia & $\mathrm{EI}_{30}=321,5+36,20 \times \mathrm{Rc}$ & Pará & $-8,26$ & $-49,27$ & Oliveira Junior (1996) \\
\hline Belém & $\mathrm{EI}_{30}=8,88+0,66 \times \mathrm{p}$ & Pará & $-1,46$ & $-48,50$ & Oliveira Junior (1988) \\
\hline Goiânia & $\mathrm{EI}_{30}=216,15+30,762 \times \mathrm{Rc}$ & Goiás & $-16,68$ & $-49,25$ & Silva et al. (1997a) \\
\hline Juazeiro & $\mathrm{EI}_{30}=42,31 \times \mathrm{Rc}+69,76$ & Bahia & $-9,57$ & $-40,31$ & Silva (2004) \\
\hline Canarana & $\mathrm{EI}_{30}=121,18 \times \mathrm{Rc}^{0,622}$ & Mato Grosso & $-13,55$ & $-52,17$ & Almeida (2009) \\
\hline Matupá & $\mathrm{EI}_{30}=115,72 \times \mathrm{Rc}^{0,746}$ & Mato Grosso & $-10,06$ & $-54,93$ & Almeida (2009) \\
\hline
\end{tabular}

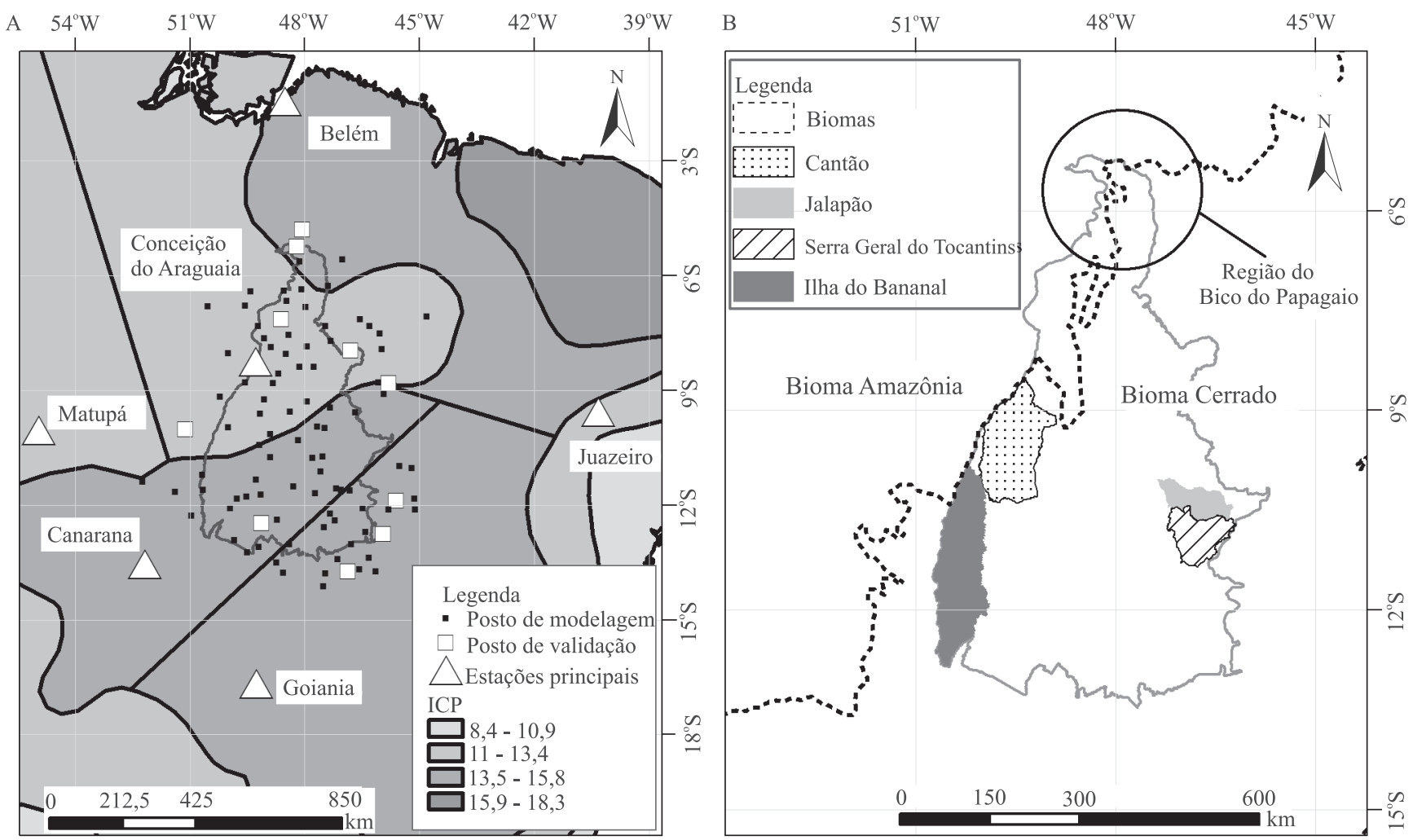

Figura 1. Localização das estações principais, banco de dados e respectivas áreas de influência determinadas pelo índice de concentração da precipitação (ICP) (adaptado de Mello et al., 2013) e pelos polígonos de Thiessen (A), e algumas regiões de interesse no Estado e os biomas Amazônia e Cerrado (B) (Tocantins, 2012). 
as equações apresentadas na Tabela 1. Para cada localidade, foi calculado o índice de erosividade anual pelo somatório dos valores mensais, tendo-se aplicado a geoestatística para o mapeamento da erosividade mensal e anual. A semivariância foi calculada por:

$$
\gamma^{*}(\mathrm{~h})=\frac{1}{2 \mathrm{~N}(\mathrm{~h})} \times \sum_{\mathrm{i}=1}^{\mathrm{N}(\mathrm{h})}\left[\mathrm{Z}\left(\mathrm{x}_{\mathrm{i}}\right)-\mathrm{Z}\left(\mathrm{x}_{\mathrm{i}+\mathrm{h}}\right)\right]^{2},
$$

em que $\gamma^{*}(h)$ é a semivariância e $\mathrm{N}(\mathrm{h})$ é o número de pares de valores observados, $\mathrm{Z}\left(\mathrm{x}_{\mathrm{i}}\right)$ e $\mathrm{Z}\left(\mathrm{x}_{\mathrm{i}+\mathrm{h}}\right)$, separados por um vetor $h$.

Após determinado o semivariograma experimental, o método dos mínimos quadrados ponderados foi utilizado para ajustar os modelos teóricos de semivariograma esférico e exponencial, os quais têm apresentado bom desempenho em estudos ambientais, inclusive para a erosividade (Mello et al., 2007, 2013; Melo et al., 2009; Silva et al., 2010; Aquino et al., 2012; Khorsandi et al., 2012). Os modelos esférico e exponencial são dados, respectivamente, por:

$$
\begin{gathered}
\gamma(\mathrm{h})=\mathrm{C}_{0}+\mathrm{C}_{1}\left[\frac{3}{2}\left(\frac{\mathrm{h}}{\mathrm{a}}\right)-\frac{1}{2}\left(\frac{\mathrm{h}}{\mathrm{a}}\right)^{3}\right] ; 0<\mathrm{h}<\mathrm{a}, \mathrm{e} \\
\gamma(\mathrm{h})=\mathrm{C}_{0}+\mathrm{C}_{1}\left[1-\exp \left(-3 \frac{\mathrm{h}}{\mathrm{a}}\right)\right] ; 0<\mathrm{h}<\mathrm{a},
\end{gathered}
$$

em que $\mathrm{C}_{0}$ é o efeito pepita; $\mathrm{C}_{1}$ é a contribuição; e a é o alcance do semivariograma.

Para selecionar o modelo de semivariograma a ser aplicado no mapeamento da erosividade, para cada uma das situações analisadas, foram realizados estudos preliminares. Calculou-se o erro médio percentual absoluto (Empa) entre os valores estimados pela geoestatística e os valores calculados para as estações de validação. Cabe ressaltar que essas comparações foram realizadas para o conjunto de dados de dez postos pluviométricos (Figura 1), escolhidos aleatoriamente e desconhecidos do processo de modelagem do semivariograma. Para selecionar aleatoriamente os postos de validação, foi aplicada a ferramenta de seleção aleatória "Create Random Selection" disponível na extensão "Hawths Tools" do ArcMap (Environmental Systems Research Institute, 2004). O cálculo do Empa foi obtido pela seguinte equação:

$$
\text { Empa }(\%)=\frac{1}{n} \times \sum_{i=1}^{n}\left|\frac{\mathrm{Obs}_{\mathrm{i}}-\text { Est }_{\mathrm{i}}}{\mathrm{Obs}_{\mathrm{i}}}\right| \times 100,
$$

Pesq. agropec. bras., Brasília, v.49, n.2, p.125-135, fev. 2014 DOI: 10.1590/S0100-204X2014000200007 em que $\mathrm{Obs}_{\mathrm{i}}$ representa o valor de erosividade calculado para o posto de validação i; Est ${ }_{i}$ é o valor de erosividade estimado pela krigagem ordinária para o posto de validação $\mathrm{i}$; e n é o número de postos pluviométricos de validação. Outro importante aspecto da análise geoestatística refere-se à verificação da qualidade do ajuste do modelo teórico de semivariograma, por meio da interpretação do grau de dependência espacial (GD), o qual reflete a estrutura de continuidade espacial, uma vez que é obtido pela relação entre a variância estrutural e o patamar (Cambardella et al., 1994).

Após os ajustes dos modelos, procedeu-se à interpolação dos dados, a partir do modelo de semivariograma que produziu o menor Empa para cada análise, por meio da krigagem ordinária, tendose gerado os mapas que mostram o comportamento espacial da erosividade da chuva no Estado do Tocantins. O programa GeoR (Ribeiro Junior \& Diggle, 2001) foi utilizado para as etapas descritas para as análises geoestatísticas. Os mapas foram gerados com uso do programa ArcMap (Environmental Systems Research Institute, 2004), tendo-se aplicado o modelo de semivariograma previamente ajustado.

\section{Resultados e Discussão}

Houve distinção de dois períodos bem definidos em relação à precipitação, com um período chuvoso de outubro a abril, e um período seco, de maio a setembro, em que a precipitação média não ultrapassou $100 \mathrm{~mm}$ por mês (Figura 2). De acordo com o ICP (Figura 1), o

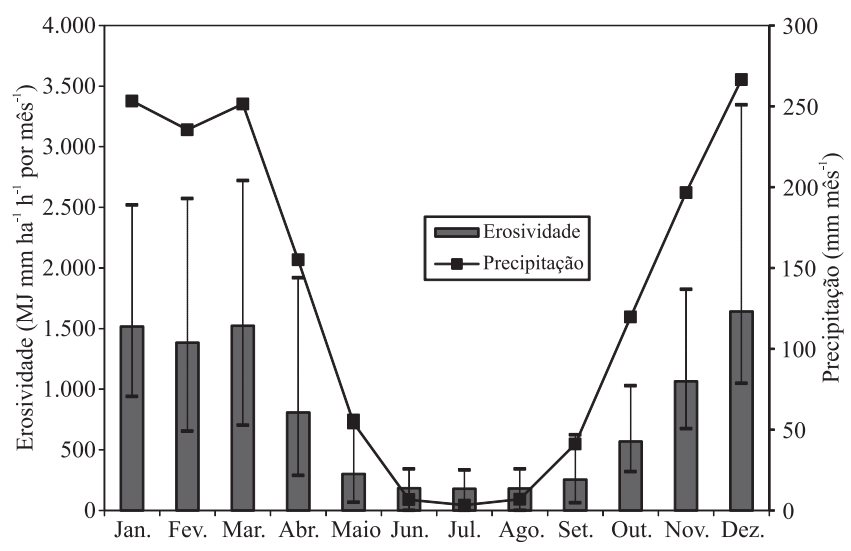

Figura 2. Médias mensais de precipitação e erosividade entre 1985 e 2009, para os 87 postos utilizados no processo de modelagem, no Estado do Tocantins. As barras de intervalo pontilhadas representam a faixa de variação mensal da erosividade. 
Estado do Tocantins apresenta sazonalidade moderada quanto à concentração de chuvas, com valores de ICP entre 11 e 15,8 (Mello et al., 2013), o que caracteriza duas regiões distintas. Na primeira, as chuvas são mais bem distribuídas ao longo do ano, em uma extensa faixa desde o norte da Ilha do Bananal (sudoeste do Estado) até o sul da região do Bico do Papagaio; e, na segunda, as chuvas encontram-se mais concentradas, cobrindo todo o sul e o extremo norte do Estado. Essa sazonalidade em relação à precipitação é uma característica marcante da região central do Brasil, na qual, durante o período de estiagem, ocorre a intensificação do anticiclone do Atlântico Sul, com redução da presença de vapor d'água na atmosfera, o que impede a organização de nuvens de chuva e o deslocamento de sistemas frontais (Reboita et al., 2010). Em termos médios para o Estado, os meses mais chuvosos corresponderam àqueles entre dezembro e março, com lâmina média acumulada que ultrapassou $1.000 \mathrm{~mm}$ (Figura 2). A erosividade nesse período correspondeu a $63,1 \%$ do total anual e mostrou que, nesses quatro meses, concentra-se o período crítico de impacto erosivo das chuvas. Destaca-se ainda que, em quase todo o período chuvoso, os valores médios de erosividade mensal ultrapassaram os $500 \mathrm{MJ} \mathrm{mm}$ ha $^{-1} \mathrm{~h}^{-1}$ por mês, considerado crítico por Silva et al. (1997b), pois acima desse limiar podem ocorrer perdas de solo superiores ao limite tolerado. Nesse período, torna-se essencial a manutenção do solo com cobertura vegetal para reduzir as ações erosivas da chuva e, consequentemente, as elevadas perdas de solo.

A variação sazonal do regime pluvial também é acompanhada de ampla variação espacial, uma vez que o Estado do Tocantins apresenta grande extensão territorial, abrangendo diferentes biomas e áreas de tensão ecológica sob distintas condições climáticas (Tocantins, 2012). O centro-oeste e o noroeste do Estado apresentam características do clima da região sudeste da Amazônia (Figura 1 B), com a formação de linhas de instabilidade em decorrência do forte processo de convecção forçada pela circulação de brisa marítima (Marengo \& Nobre, 2009) e valores de precipitação anual de até $2.100 \mathrm{~mm}$ (Tocantins, 2012). Outro importante mecanismo ligado à elevada lâmina precipitada nas regiões centro-oeste e noroeste do Estado relaciona-se à flutuação da Zona de Convergência Intertropical, que resulta em atividade convectiva intensa durante o verão (Melo et al., 2009; Reboita et al., 2010). Entretanto, no sul do Estado, os valores de precipitação permanecem na ordem de $1.300 \mathrm{~mm}$ (Tocantins, 2012), o que deixa nítida a heterogeneidade inerente ao regime pluvial no Tocantins e atenta para a necessidade de se descrever adequadamente o padrão espaço-temporal da erosividade.

O modelo de semivariograma exponencial apresentou menor Empa em nove análises, enquanto o modelo esférico se sobressaiu apenas em janeiro, março, setembro e outubro (Tabela 2). Nota-se que o Empa foi menor que 20\% para a maioria dos meses e apresentou valores máximos para julho e agosto. A grande variação nesses meses está associada aos baixos valores de erosividade no período seco, o que faz com que os erros absolutos assumam magnitudes elevadas. Para a erosividade anual, o valor do Empa foi de 11,51\%. As Figuras 3 e 4 apresentam os modelos de semivariograma com menor Empa para cada

Tabela 2. Erro médio percentual absoluto (Empa), alcance, efeito pepita $\left(\mathrm{C}_{0}\right)$, patamar $\left(\mathrm{C}_{0}+\mathrm{C}_{1}\right)$ e grau de dependência espacial (GDE) para os modelos de semivariograma exponencial e esférico.

\begin{tabular}{|c|c|c|c|c|c|c|c|c|c|c|c|c|c|}
\hline Parâmetro & Jan. & Fev. & Mar. & Abr. & Maio & Jun. & Jul. & Ago. & Set. & Out. & Nov. & Dez. & Anual \\
\hline \multicolumn{14}{|c|}{ Modelo exponencial } \\
\hline Empa (\%) & 14,2 & 15,7 & 12,5 & 16,6 & 14,4 & 18,7 & 29,8 & 24,5 & 16,1 & 15,6 & 14,1 & 14,2 & 11,5 \\
\hline Alcance $(\mathrm{km})$ & 210,6 & 213,8 & 333,8 & 758,9 & 400,0 & 569,0 & 555,6 & 552,7 & 704,2 & $1.125,4$ & 370,7 & 264,5 & 656,4 \\
\hline $\mathrm{C}_{0}$ & 0,0 & $32.823,2$ & $3.497,2$ & $14.207,6$ & 0,0 & 0,0 & 0,0 & 0,0 & 0,0 & 0,0 & 0,0 & 0,0 & 0,0 \\
\hline $\mathrm{C}_{0}+\mathrm{C}_{1}$ & $122.180,3$ & $110.405,6$ & $106.004,0$ & $43.332,7$ & $11.715,4$ & $21.922,1$ & $22.528,0$ & $21.905,0$ & $15.420,2$ & $44.201,3$ & $62.049,0$ & $148.777,0$ & $6.755 .188,9$ \\
\hline GDE & 100,0 & 70,3 & 96,7 & 67,2 & 100,0 & 100,0 & 100,0 & 100,0 & 100,0 & 100,0 & 100,0 & 100,0 & 100,0 \\
\hline \multicolumn{14}{|c|}{ Modelo esférico } \\
\hline Empa (\%) & 13,2 & 16,8 & 12,0 & 16,8 & 15,0 & 45,5 & 42,7 & 26,4 & 15,6 & 15,5 & 14,8 & 15,6 & 11,9 \\
\hline Alcance (km) & 180,0 & 336,0 & 392,4 & 614,4 & 357,8 & 362,0 & 357,2 & 358,3 & 383,9 & 564,4 & 306,8 & 297,8 & 451,9 \\
\hline $\mathrm{C}_{0}$ & $4.831,0$ & $71.680,4$ & $36.506,0$ & $19.352,2$ & 0,0 & 0,0 & 0,0 & 0,0 & 0,0 & 0,0 & $5.764,6$ & $42.952,8$ & $91.710,5$ \\
\hline $\mathrm{C}_{0}+\mathrm{C}_{1}$ & $120.201,1$ & $111.122,9$ & $105.519,9$ & $40.855,0$ & $11.564,7$ & $19.236,6$ & $19.875,9$ & $19.372,4$ & $12.593,6$ & $34.281,2$ & $58.634,6$ & $147.436,3$ & $6.113 .251,7$ \\
\hline GDE & 96,0 & 35,5 & 65,4 & 52,6 & 100,0 & 100,0 & 100,0 & 100,0 & 100,0 & 100,0 & 90,2 & 70,9 & 98,5 \\
\hline
\end{tabular}



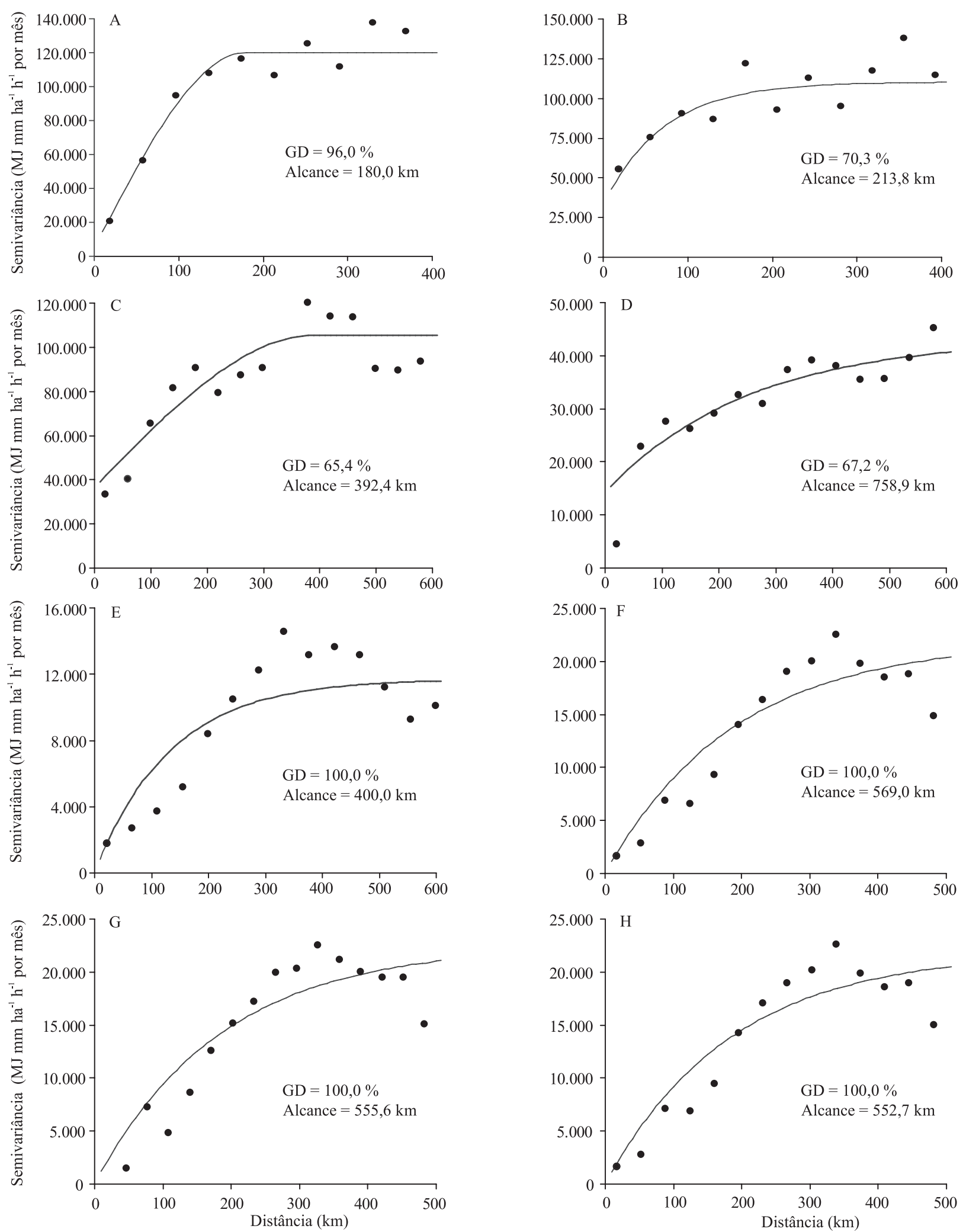

Figura 3. Modelos de semivariograma ajustados para erosividade em janeiro (A), fevereiro (B), março (C), abril (D), maio (E), junho (F), julho (G) e agosto (H), no Estado do Tocantins. GD = grau de dependência. 
análise. Pode-se visualizar boa aderência dos modelos teóricos aos semivariogramas experimentais, com forte estrutura de dependência espacial, com valores de grau de dependência (GD) superiores a $75 \%$ na maioria das análises (Cambardella et al., 1994). Esse forte grau de dependência não foi verificado para fevereiro, março e abril, contudo, o valor obtido foi muito próximo a esse limite. $\mathrm{O}$ alcance da estrutura de dependência espacial variou entre 180 (janeiro) e $758,9 \mathrm{~km}$ (abril), o que indica que as técnicas geoestatísticas podem produzir bons resultados no mapeamento da erosividade no Estado do Tocantins.
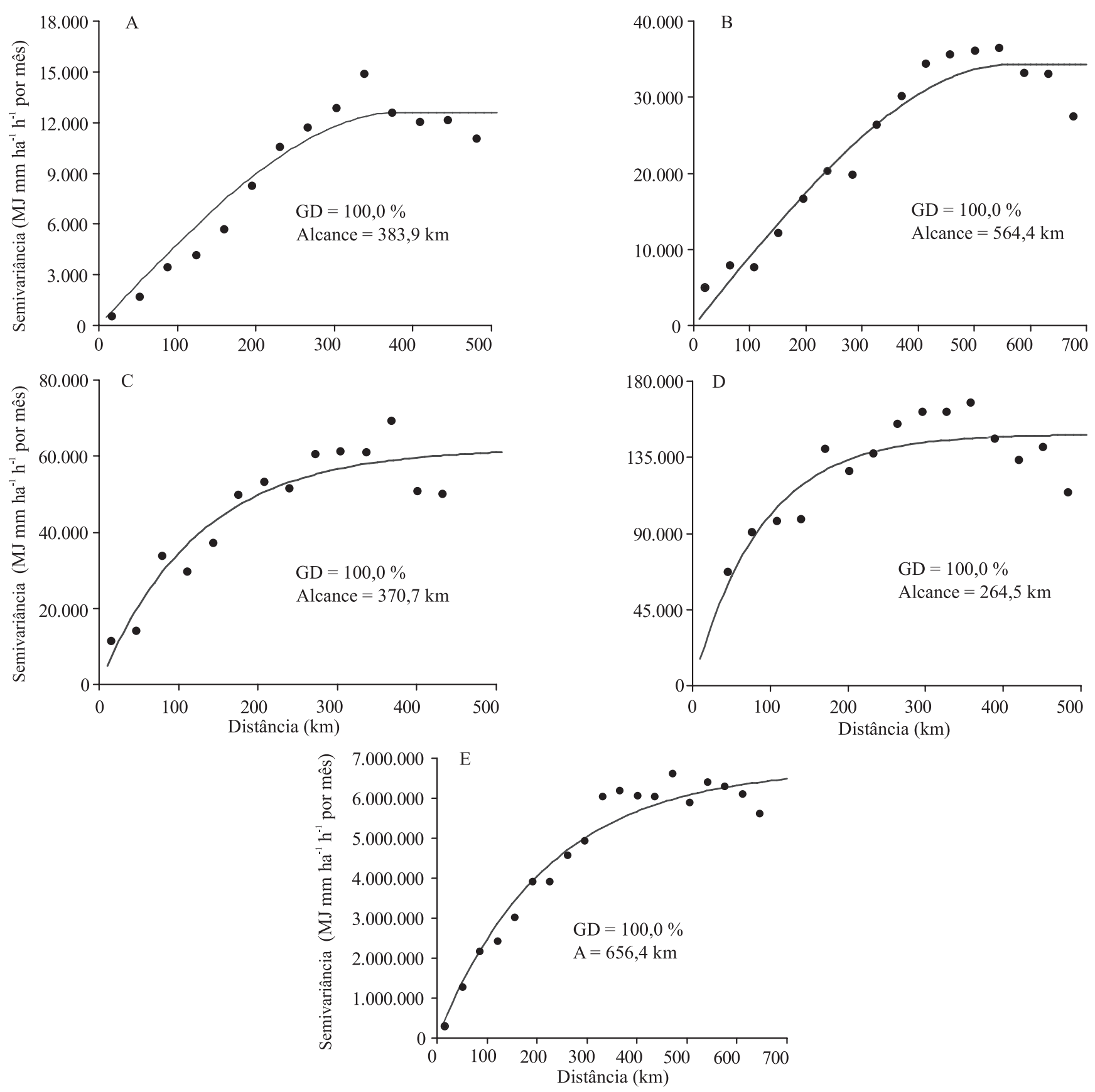

Figura 4. Modelos de semivariograma ajustados para erosividade em setembro (A), outubro (B), novembro (C), dezembro (D) e para erosividade anual (E), no Estado do Tocantins. GD = grau de dependência. 
No primeiro trimestre, a zona de maior erosividade localiza-se na região conhecida como Cantão, no centro-oeste do Estado, e também em uma pequena área ao norte do Estado (Figura $5 \mathrm{~A}, \mathrm{~B}$ e C). Na região do Cantão, ocorreram as maiores magnitudes de erosividade em janeiro e fevereiro, com valores de até 2.200 MJ mm ha- $\mathrm{M}^{-1}$ por mês. Nesse trimestre, a maior erosividade mensal foi encontrada para março, para o sul da região do Bico do Papagaio, tendo chegado a $2.400 \mathrm{MJ} \mathrm{mm} \mathrm{ha}^{-1} \mathrm{~h}^{-1}$ por mês. Contudo, a área do
Estado com elevada erosividade em março abrangeu uma pequena porção territorial. Já no segundo trimestre, a região de maior erosividade desloca-se para o norte do Estado (Figura $5 \mathrm{D}, \mathrm{E}$ e F), na região do Bico do Papagaio. Observa-se que, em maio, apenas a região do Bico do Papagaio apresentou valores críticos (acima de $500 \mathrm{MJ} \mathrm{mm} \mathrm{ha}^{-1} \mathrm{~h}^{-1}$ por mês), o que requer especial atenção para o planejamento do uso do solo. Em junho, todo o Estado apresentou valores inferiores ao crítico, o que indica o início do período de menor
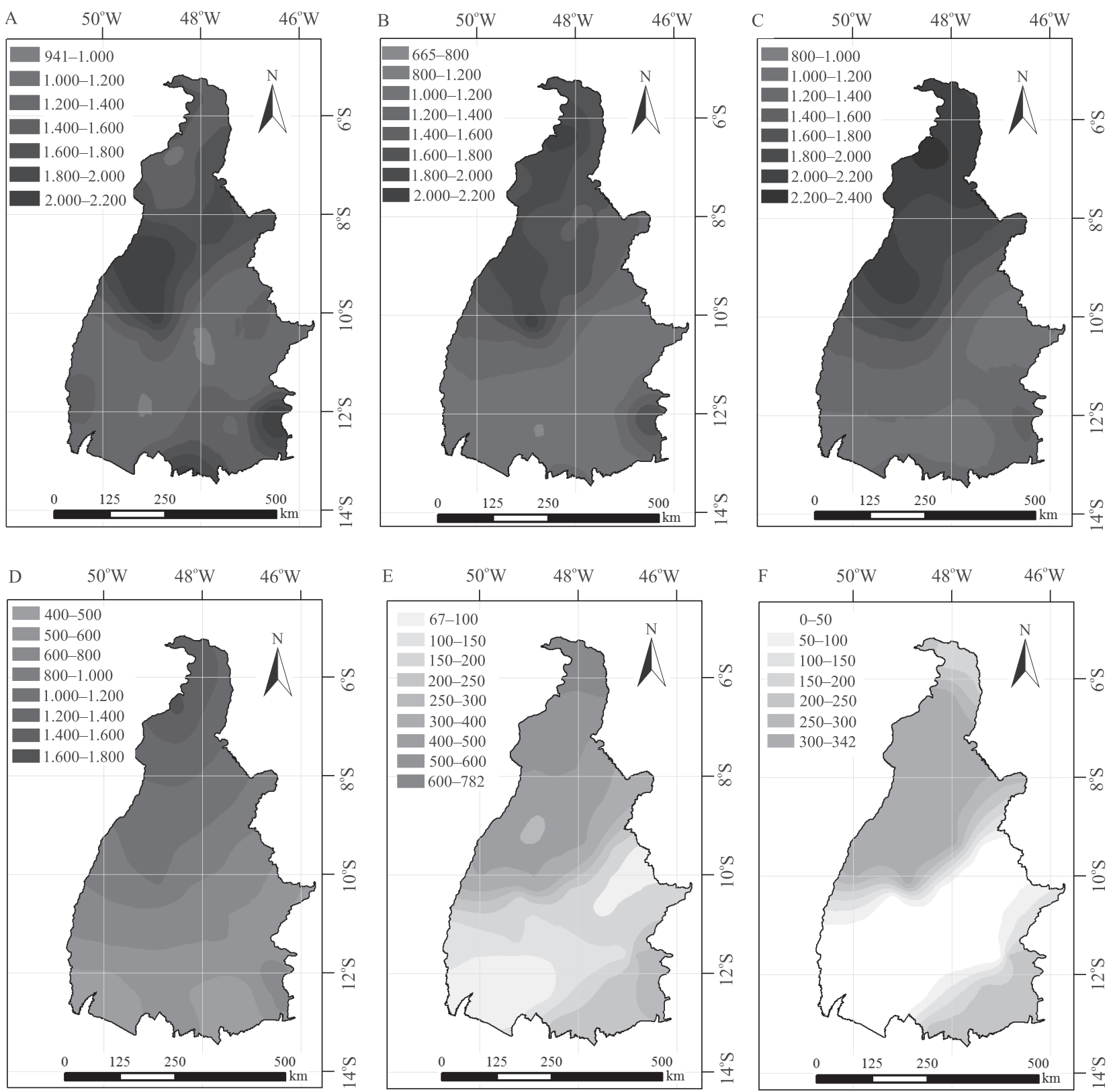

Figura 5. Mapas de erosividade média ( $\mathrm{MJ} \mathrm{mm} \mathrm{ha}^{-1} \mathrm{~h}^{-1}$ por mês) para o período de 1985 a 2009, para janeiro (A), fevereiro (B), março (C), abril (D), maio (E) e junho (F), no Estado do Tocantins. 
potencial erosivo das chuvas, que se estende por todo o próximo trimestre (Figura $6 \mathrm{~A}, \mathrm{~B}$ e $\mathrm{C}$ ).

No quarto trimestre do ano, quando o potencial erosivo volta a assumir valores críticos, o comportamento geral foi diferenciado daquele obtido para o primeiro trimestre. A região sudeste, nas proximidades da Serra Geral, representou a região de maior índice de erosividade, com a região do Cantão (Figura 6 D, E e F). Dessa maneira, embora, nesse período, a região do Bico do Papagaio apresente valores críticos de $\mathrm{EI}_{30}$, esta deixou de integrar a região de maior $\mathrm{EI}_{30}$ no Estado, sobretudo em novembro e dezembro. É interessante observar que dezembro apresentou os maiores valores de erosividade, que chegaram a até $2.800 \mathrm{MJ} \mathrm{mm} \mathrm{ha}^{-1} \mathrm{~h}^{-1}$ por mês.

$\mathrm{O}$ valor de erosividade anual variou de 6.599 a 14.000 $\mathrm{MJ} \mathrm{mm} \mathrm{ha}{ }^{-1} \mathrm{~h}^{-1}$ por ano (Figura 7). A região do Cantão apresentou os maiores valores de $\mathrm{EI}_{30}$,
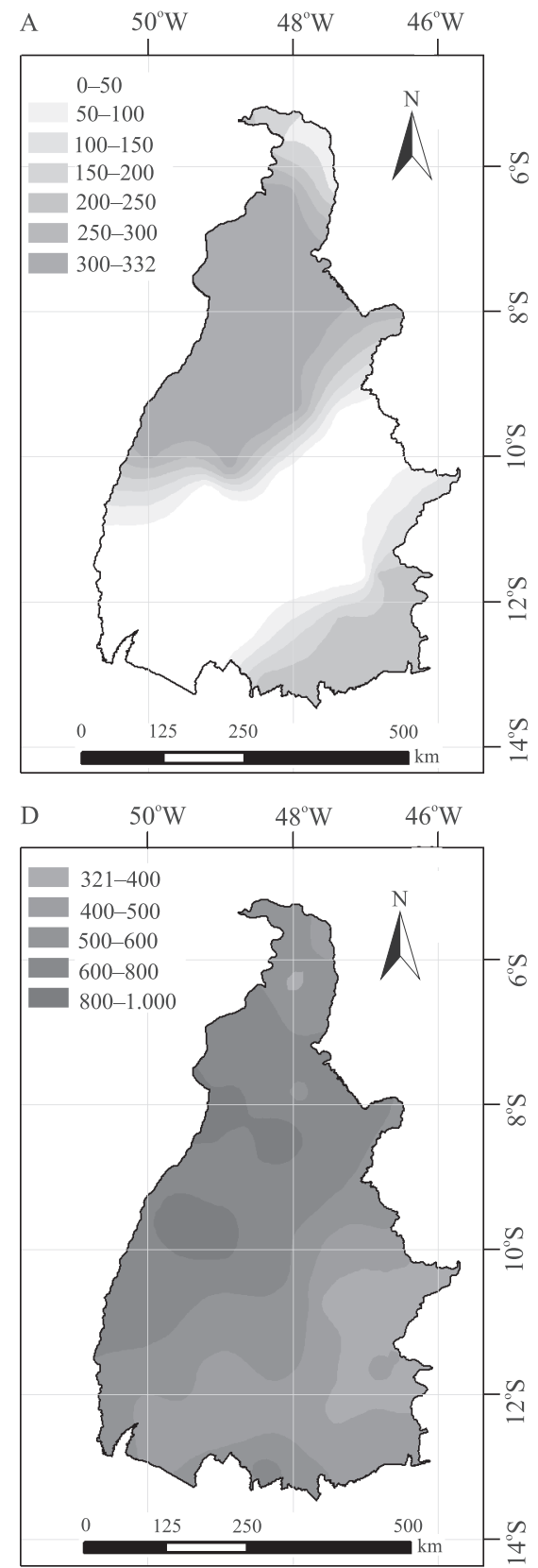
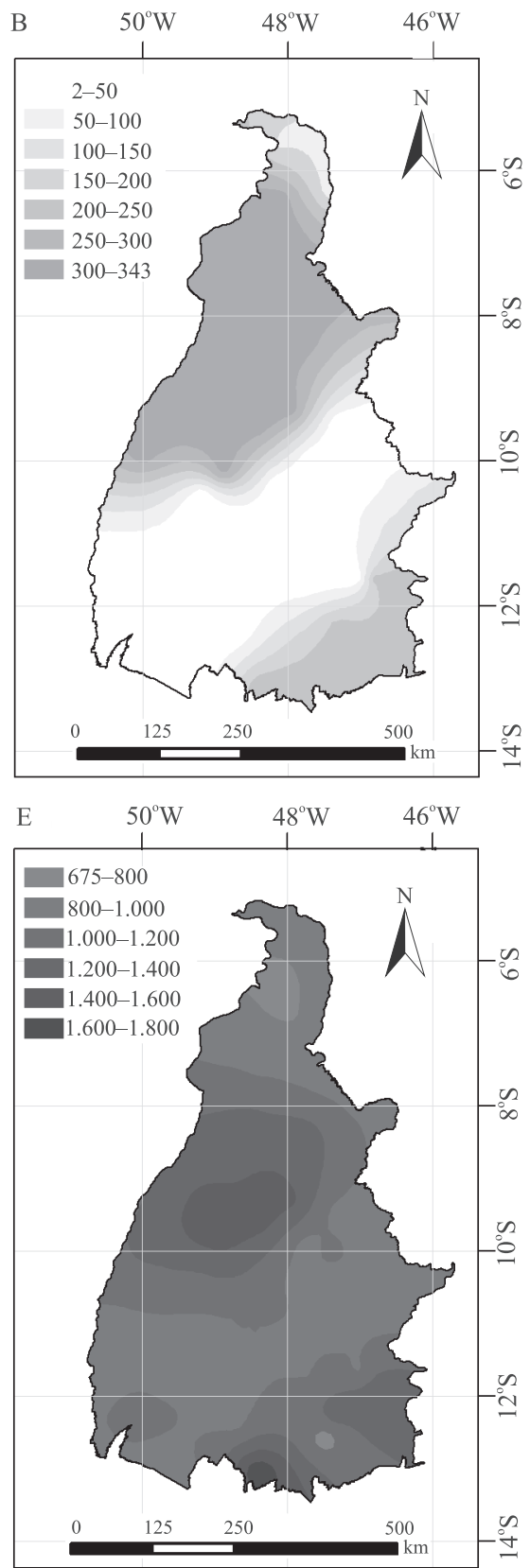
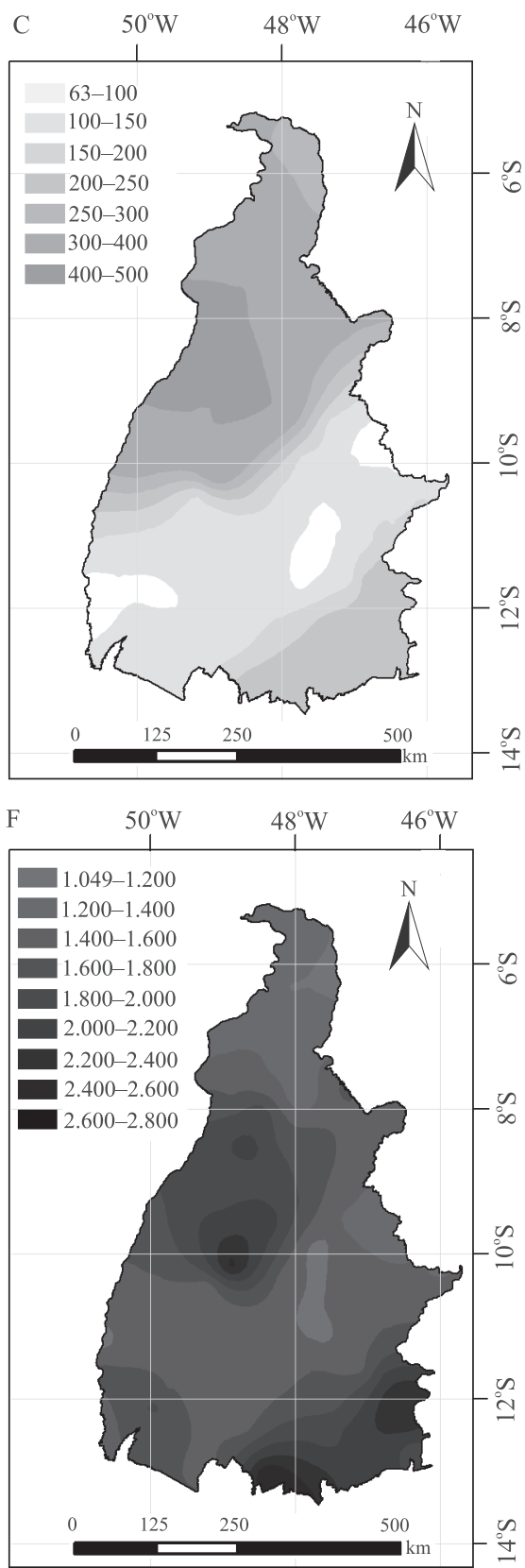

Figura 6. Mapas de erosividade média ( $\mathrm{MJ} \mathrm{mm} \mathrm{ha}^{-1} \mathrm{~h}^{-1}$ por mês) para o período de 1985 a 2009, para julho (A), agosto (B), setembro (C), outubro (D), novembro (E) e dezembro (F), no Estado do Tocantins. 


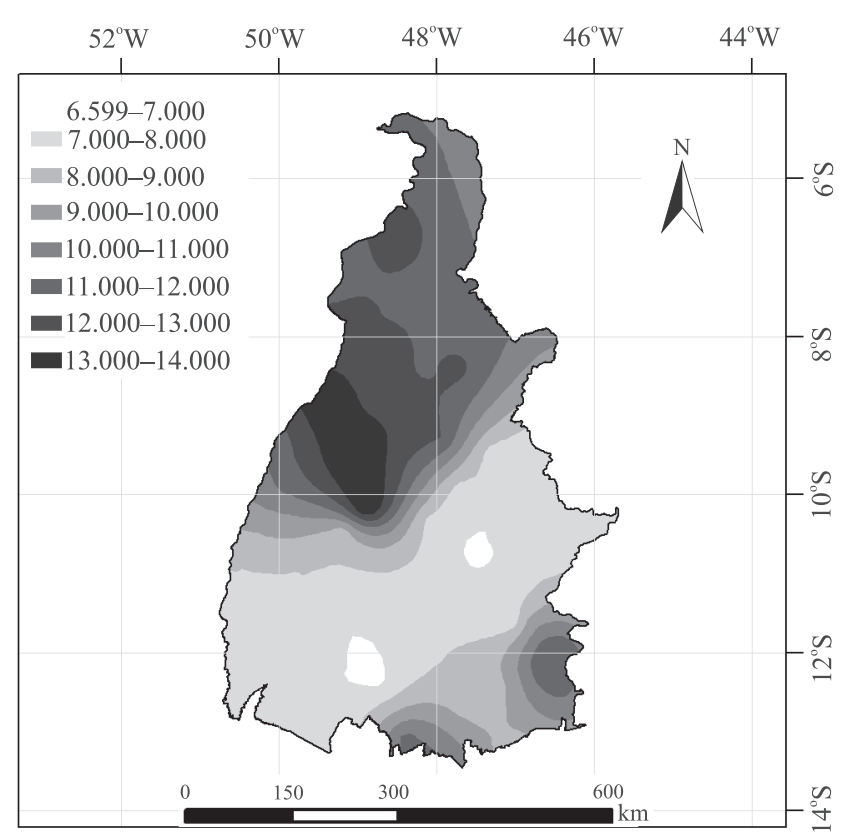

Figura 7. Mapa de erosividade média anual (MJ mm ha ${ }^{-1} \mathrm{~h}^{-1}$ por ano) entre 1985 e 2009, para o Estado do Tocantins.

enquanto uma faixa do território, que se estende da região sudoeste em direção ao centro-leste, produziu os menores valores. Comportamento intermediário foi obtido para o extremo sudeste e o norte da região do Cantão.

O mapeamento da erosividade da chuva, tanto em escala mensal quanto anual, identificou regiões e períodos críticos em relação ao potencial erosivo das chuvas. Essas informações fornecem subsídios para o planejamento, em macroescala, de uso e manejo sustentável do solo, bem como para a implementação de ações para a conservação do solo e da água para o Estado do Tocantins.

\section{Conclusões}

1. A erosividade das chuvas no Estado do Tocantins, tanto na escala de tempo mensal quanto anual, apresenta estrutura de continuidade espacial entre moderada e forte, com alcance entre 180 e $758,9 \mathrm{~km}$.

2. A erosividade anual da chuva para o Estado do Tocantins apresenta valores de até 14.000 MJ mm ha ${ }^{-1} \mathrm{~h}^{-1}$ por ano, e a região do Parque Estadual do Cantão apresenta os maiores valores anuais.
3. A região de maior potencial erosivo se desloca ao longo do ano no Estado do Tocantins, e dezembro apresenta os maiores valores, com até $2.800 \mathrm{MJ} \mathrm{mm}$ $\mathrm{ha}^{-1} \mathrm{~h}^{-1}$ por mês.

4. A erosividade mensal apresenta valores inferiores ao crítico (500 $\mathrm{MJ} \mathrm{mm} \mathrm{ha}^{-1} \mathrm{~h}^{-1}$ por mês) em maio, junho, julho, agosto e setembro.

\section{Referências}

ALMEIDA, C.O.S. de. Erosividade das chuvas no Estado de Mato Grosso. 2009. 83p. Dissertação (Mestrado) - Universidade de Brasília, Brasília.

AQUINO, R.F.; SILVA, M.L.N.; FREITAS, D.A.F. de; CURI, N.; MELLO, C.R.; AVANZI, J.C. Spatial variability of the rainfall erosivity in southern region of Minas Gerais State, Brazil. Ciência e Agrotecnologia, v.36, p.533-542, 2012. DOI: 10.1590/ S1413-70542012000500006.

CAMBARDELLA, C.A.; MOORMAN, T.B.; PARKIN, T.B.; KARLEN, D.L.; NOVAK, J.M.; TURCO, R.F.; KONOPKA, A.E. Field-scale variability of soil properties in Central Iowa Soils. Soil Science Society of America Journal, v.58, p.1501-1511, 1994. DOI: $10.2136 /$ sssaj1994.03615995005800050033x.

DIODATO, N.; KNIGHT, J.; BELLOCCHI, G. Reduced complexity model for assessing patterns of rainfall erosivity in Africa. Global and Planetary Change, v.100, p.183-193, 2013. DOI: 10.1016/j.gloplacha.2012.10.016.

ENVIRONMENTAL SYSTEMS RESEARCH INSTITUTE. ArcGIS 9: getting started with ArcGIS. Redlands: ESRI, 2004. 265p.

GOOVAERTS, P. Using elevation to aid the geostatistical mapping of rainfall erosivity. Catena, v.34, p.227-242, 1999. DOI: 10.1016/ S0341-8162(98)00116-7.

KHORSANDI, N.; MAHDIAN, M.H.; PAZIRA, E.; NIKKAMI, D.; CHAMHEIDAR, H. Comparison of different interpolation methods for investigating spatial variability of rainfall erosivity index. Polish Journal of Environmental Studies, v.21, p.1659-1666, 2012.

MARENGO J.A.; NOBRE, C. Clima da região amazônica. In: CAVALCANTI, I.F.A.; FERREIRA, N.J.; DIAS, M.A.F.; JUSTI, M.G.A. (Org.). Tempo e clima no Brasil. São Paulo: Oficina de Textos, 2009. p.198-212.

MELLO, C.R. de; SÁ, M.A.C. de; CURI, N.; MELLO, J.M. de; VIOLA, M.R.; SILVA,A.M. da. Erosividade mensal e anual da chuva no Estado de Minas Gerais. Pesquisa Agropecuária Brasileira, v.42, p.537-545, 2007. DOI: 10.1590/S0100-204X2007000400012.

MELlO, C.R. de; VIOLA, M.R.; CURI, N.; SILVA, A.M. da. Distribuição espacial da precipitação e da erosividade da chuva mensal e anual no Estado do Espírito Santo. Revista Brasileira de Ciência do Solo, v.36, p.1878-1891, 2012. DOI: 10.1590/ S0100-06832012000600022.

MELLO, C.R.; VIOLA, M.R.; BESKOW, S.; NORTON, L.D. Multivariate models for annual rainfall erosivity in Brazil. 
Geoderma, v.202-203, p.88-102, 2013. DOI: 10.1016/j. geoderma.2013.03.009.

MELO, A.B.C.; CAVALCANTI, I.F.A.; SOUZA, P.P. Zona de convergência intertropical do atlântico. In: CAVALCANTI, I.F.A.; FERREIRA, N.J.; DIAS, M.A.F.; JUSTI, M.G.A. (Org.). Tempo e clima no Brasil. São Paulo: Oficina do Texto, 2009. p.26-41.

MICHIELS, P.; GABRIELS, D.; HARTMANN, R. Using the seasonal and temporal precipitation concentration index for characterizing the monthly rainfall distribution in Spain. Catena, v.19, p.43-58, 1992. DOI: 10.1016/0341-8162(92)90016-5.

MONTEBELlER, C.A.; CEDDIA, M.B.; CARVALHO, D.F. de; VIEIRA, S.R.; FRANCO, E.M. Variabilidade espacial do potencial erosivo das chuvas no Estado do Rio de Janeiro. Engenharia Agrícola, v.27, p.426-435, 2007. DOI: 10.1590/ S0100-69162007000300011.

OLIVEIRA JUNIOR, R.C. de. A erosividade das chuvas na parte leste do Estado do Pará. 1988. 52p. Dissertação (Mestrado) - Universidade Federal Rural da Amazônia, Belém.

OLIVEIRA JUNIOR, R.C. de. Índice de erosividade das chuvas na região de Conceição do Araguaia, Pará. Belém: Embrapa-CPATU, 1996. 20p. (Embrapa-CPATU. Boletim de pesquisa, 165).

OLIVEIRA, P.T.S.; RODRIGUES, D.B.B.; A. SOBRINHO, T.; CARVALHO, D.F. de; PANACHUKI, E. Spatial variability of the rainfall erosive potential in the State of Mato Grosso do Sul, Brazil. Engenharia Agrícola, v.32, p.69-79, 2012a. DOI: 10.1590/ S0100-69162012000100008.

OLIVEIRA, P.T.S.; WENDLAND, E.; NEARING, M.A. Rainfall erosivity in Brazil: a review. Catena, v.100, p.139-147, 2012 b. DOI: 10.1016/j.catena.2012.08.006.

OLIVER, J.E. Monthly precipitation distribution: a comparative index. Professional Geographer, v.32, p.300-309, 1980. DOI: 10.1111/j.0033-0124.1980.00300.x.

PETAN, .S; RUSJAN, S.; VIDMAR, A.; MIKOŠ, M. The rainfall kinetic energy-intensity relationship for rainfall erosivity estimation in the mediterranean part of Slovenia. Journal of Hydrology, v.391, p.314-321, 2010. DOI: 10.1016/j.jhydrol.2010.07.031.

REBOITA, M.S.; GAN, M.A.; ROCHA, R.P. da; AMBRIZZI, T. Regimes de precipitação na América do Sul: uma revisão bibliográfica. Revista Brasileira de Meteorologia, v.25, p.185-204, 2010. DOI: 10.1590/S0102-77862010000200004.
RENARD, K.G.; FREIMUND, J.R. Using monthly precipitation data to estimate the R-factor in the revised USLE. Journal of Hydrology, v.157, p.287-306, 1994. DOI: 10.1016/0022-1694(94)90110-4.

RIBEIRO JUNIOR, P.J.; DIGGLE, P.J. GeoR: a package for geostatistical analysis. R News, v.1, p.15-18, 2001.

SANCHEZ-MORENO, J.F.; MANNAERTS, C.M.; JETTEN, V. Rainfall erosivity mapping for Santiago Island, Cape Verde. Geoderma, v.217-218, p.74-82, 2014. DOI: 10.1016/j. geoderma.2013.10.026.

SILVA, A.M. Rainfall erosivity map for Brazil. Catena, v.57, p.251-259, 2004. DOI: 10.1016/j.catena.2003.11.006.

SILVA, M.L.N.; FREITAS, P.L. de; BLANCANEAUX, P.; CURI, $\mathrm{N}$. Índices de erosividade das chuvas da região de Goiânia, GO. Pesquisa Agropecuária Brasileira, v.32, p.977-985, 1997a.

SILVA, M.L.N.; FREITAS, P.L. de; BLANCANEAUX, P.; CURI, N.; LIMA, J.M. Relação entre parâmetros da chuva e perdas de solo e determinação da erodibilidade de um Latossolo Vermelho-Escuro em Goiânia (GO). Revista Brasileira de Ciência do Solo, v.21, p.131-137, 1997b.

SILVA, S. de A.; LIMA, J.S. de S.; SOUZA, G.S. de; OLIVEIRA, R.B. de. Variabilidade espacial do potencial erosivo das chuvas para o estado do Espírito Santo, Brasil. Irriga, v.15, p.312-323, 2010.

TOCANTINS. Secretaria do Planejamento e da Modernização da Gestão Pública. Superintendência de Pesquisa e Zoneamento Ecológico-Econômico. Diretoria de Zoneamento Ecológico-Econômico. Atlas do Tocantins: subsídios ao planejamento da gestão territorial. 6.ed. rev. atual. Palmas: SEPLAN/DZE, 2012. 80p.

TUCCI, C.E.M. (Org.). Hidrologia: ciência e aplicação. 3.ed. Porto Alegre: Ed. da UFRGS: ABRH, 2004. 943p.

VIOLA, M.R.; MELLO, C.R. de; PINTO, D.B.F.; MELLO, J.M. de; ÁVILA, L.F. Métodos de interpolação espacial para o mapeamento da precipitação pluvial. Revista Brasileira de Engenharia Agrícola e Ambiental, v.14, p.970-978, 2010. DOI: 10.1590/S1415-43662010000900009.

$\overline{\text { Recebido em } 11 \text { de outubro de } 2013 \text { e aprovado em } 30 \text { de janeiro de } 2014}$ 